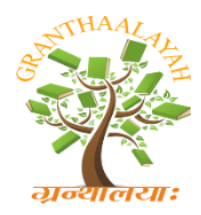

\author{
INTERNATIONAL JOURNAL OF RESEARCH - \\ GRANTHAALAYAH \\ A knowledge Repository
}

Science

\title{
GREEN CHEMISTRY: ROSELLE'S COROLLA EXTRACT AS A SUBSTITUTE FOR HAZARDOUS INTERNAL INDICATORS IN VOLUMETRIC ANALYSIS
}

\author{
Dr. R. F. Pagariya *1 \\ ${ }^{* 1}$ Department of Chemistry, R. A. Arts, M. K. Commerce and Shri S. R. Rathi Science College, \\ Washim, 444505 India
}

\begin{abstract}
Indicators used in acid-base titration show well marked changes of colour in certain intervals of $\mathrm{pH}$. Most of these indicators are organic dyes and are of synthetic origin. Today synthetic indicators are the choice of neutralization titrations. But due to environmental pollution, availability and cost, the search for natural compounds as an acid-base indicator was started. The present work highlights the use of the ethanolic extract of the corolla of Roselle (Hibiscus sabdariffa) as a $\mathrm{pH}$ indicator in strong acid-strong base, strong acid weak base, weak acid strong base and weak acid-weak base titrations. This natural indicator is easy to extract as well as easily available. The results showed that the Roselle's corolla indicator gave red color in acidic solution, while green in basic solution. The comparison indicators used in this research were phenolphthalein, methyl red and phenol red. Hopeful results were obtained when it was compared against standard synthetic indicators. The equivalence points obtained match with the equivalence points obtained by standard indicators. Therefore this natural indicator is found to be useful, economical, simple, precise and eco-friendly for acid base titration.
\end{abstract}

Keywords: Extract of Corolla of Roselle; Natural Indicator; Acid Base Indicator; Equivalence Point.

Cite This Article: Dr. R. F. Pagariya. (2019). “GREEN CHEMISTRY: ROSELLE'S COROLLA EXTRACT AS A SUBSTITUTE FOR HAZARDOUS INTERNAL INDICATORS IN VOLUMETRIC ANALYSIS." International Journal of Research - Granthaalayah, 7(9), 118-122. https://doi.org/10.29121/granthaalayah.v7.i9.2019.567.

\section{Introduction}

Roselle (Hibiscus sabdariffa) is a species of Hibiscus belongs to Malvaceae family [1], probably native to West Africa. It is an annual or perennial herb or woody-based sub-shrub, growing to 2$2.5 \mathrm{~m}(6-8 \mathrm{ft})$ tall. It is easily cultivated either in tropical or subtropical area and start flowering at the age of 3-4 months. In Maharashtra (India), Roselle is called Ambadi. The plant is primarily cultivated for the production of bast fiber from the stem. The fiber may be used as substitute for jute in making burlap. Roselle has also been used in folk medicine as a diuretic and mild laxative. 
Dried petal of Roselle is mainly used for food, beverages (tea) as well as food coloring agent, as it has been known that it contains anthocyanins pigment, delvinidin-3-monoglucosyde and cyanidin3-monoglucoside [2,3].

Apart from the uses of Roselle mentioned above, in this study it was aimed to make Roselle's corolla extract as neutralization indicator for strong acid-strong base, strong acid weak base, weak acid strong base and weak acid weak base titrations with the comparison against methyl red, phenol red and phenolphthalein. It has been hypothesized that the flower extract could be utilized as an indicator for all four types of acid base titrations [4]. The pulps of the flower petals are $\mathrm{pH}$ sensitive due to anthocyanin [5,6] content and give different colors in acidic condition (reddish) and basic condition (greenish). The equivalence points obtained by using flower extract matched with the equivalence points obtained by standard indicators.

\section{Materials and Methods}

\section{Materials}

Analytical grade reagents of Research Lab Fine Chem Industries Ltd. i.e. hydrochloric acid ( $\mathrm{HCl})$, acetic acid $\left(\mathrm{CH}_{3} \mathrm{COOH}\right)$, sodium hydroxide $(\mathrm{NaOH})$, sodium bicarbonate $\left(\mathrm{NaHCO}_{3}\right)$, phenolphthalein, methyl orange and phenol red were procured from the R. A. Arts, Shri M. K. Commerce and Shri S. R. Rathi Science College Washim (M.S.). Reagents and volumetric solutions were prepared as per Indian Pharmacopoeia. For production of acid base indicator from Roselle, the fresh Roselle flowers were bought and collected from Mahatma Fule Market, authenticated at Department of Botany, R. A. College, Washim (M.S.) and by botanical Software.

\section{Preparation of Acid Base Indicator Solution}

Corolla of Roselle (150 g) was washed with distilled water, cut into small pieces and crushed in mortar and pistol. Next, a crushed pulp of Roselle petals soaked with $150 \mathrm{~mL}$ ethyl alcohol for about 24 hours. The extract was filtered by Mussolini cloth, while the residue was re-extracted again using $50 \mathrm{ml}$ of ethyl alcohol for $24 \mathrm{hrs}$. The resulting solution is filtered through double filter and fairly pink coloured solution obtained was used as an indicator. Its $\mathrm{pH}$ rang as measured is (10.5-11.1) 10.5 at and below which it is red and 11.1 at and above which it is greenish. It was kept in dark bottle and away from any source of heat and light.

\section{Experimental}

At room temperature the titrations of Strong acid-Strong base $(\mathrm{HCl}$ versus $\mathrm{NaOH})$, Strong acidWeak base $\left(\mathrm{HCl}\right.$ versus $\left.\mathrm{NaHCO}_{3}\right)$, Weak acid Strong base $\left(\mathrm{CH}_{3} \mathrm{COOH}\right.$ versus $\left.\mathrm{NaOH}\right)$ and Weak acid-Weak base $\left(\mathrm{CH}_{3} \mathrm{COOH}\right.$ versus $\left.\mathrm{NaHCO}_{3}\right)$, both in each pair are of equal concentrations i.e. $0.25 \mathrm{M}, 0.50 \mathrm{M}$ and $1.0 \mathrm{M}$ was carried by using the same set of glassware for all titrations. As the same aliquots were used for all titrations i.e. titrations by using standard indicators methyl red, phenol red, phenolphthalein and indicator under study, the reagents were not calibrated. The equimolar titrations were performed using $10 \mathrm{ml}$ of titrant with 5 drops of indicator. The trials were repeated 3 times to check the precision. The end points of the titrations using the indicator under study were reached when colour changed from red to green. The color changes for the indicators are listed in the Tables 1 . The results of screening for all four types of acid base titrations are recorded as mean $\mathrm{t}$-value of titration $(\mathrm{ml}) \pm \mathrm{SD}$ in Table 2 . 
While preparing solutions of the weak base a little heating was given for complete dissolution of the base. When base was titrated with the weak acid, the acid was constantly stirred on a magnetic stirrer for better results. For titrations involving a weak acid-weak base our indicator was added in excess $(1.5 \mathrm{~mL})$.

Table 1: Experimental screening of Roselle's corolla extract as acid base indicator

\begin{tabular}{|l|l|l|l|}
\hline Titrant & Titrate & Indicator & Colour at End Point \\
\hline \multirow{4}{*}{$\mathrm{HCl}$} & $\mathrm{NaOH}$ & Phenolphthalein & Colorless to Pink \\
\cline { 3 - 4 } & & Methyl Red & Red to Yellow \\
\cline { 3 - 4 } & & Phenol Red & Yellow to Red \\
\cline { 3 - 4 } & & Roselle's corolla extract & Pink to Green \\
\hline $\mathrm{CH}_{3} \mathrm{COOH}$ & $\mathrm{NaHCO}_{3}$ & Phenolphthalein & Colorless to Pink \\
\cline { 3 - 4 } & & Methyl Red & Red to Yellow \\
\cline { 3 - 4 } & & Phenol Red & Yellow to Red \\
\cline { 3 - 4 } & Roselle's corolla extract & Pink to Green \\
\hline
\end{tabular}

Table 2: Experimental screening of Roselle's corolla extract as neutralization indicator

\begin{tabular}{|c|c|c|c|c|}
\hline S.N. & Titrations & Strength & Indicators & 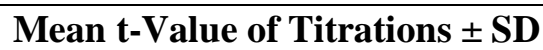 \\
\hline \multirow[t]{12}{*}{1} & \multirow{12}{*}{$\begin{array}{l}\mathrm{HCl} \\
\mathrm{Vs} \\
\mathrm{NaOH}\end{array}$} & \multirow[t]{4}{*}{$0.25 \mathrm{M}$} & Phenolphthalein & $10.09 \pm 0.059$ \\
\hline & & & Methyl red & $10.05 \pm 0.055$ \\
\hline & & & Phenol red & $10.07 \pm 0.075$ \\
\hline & & & Roselle's corolla extract & $10.09 \pm 0.069$ \\
\hline & & \multirow[t]{4}{*}{$0.50 \mathrm{M}$} & Phenolphthalein & $10.08 \pm 0.052$ \\
\hline & & & Methyl red & $10.07 \pm 0.067$ \\
\hline & & & Phenol red & $10.09 \pm 0.080$ \\
\hline & & & Roselle's corolla extract & $10.06 \pm 0.065$ \\
\hline & & \multirow[t]{4}{*}{$1.00 \mathrm{M}$} & Phenolphthalein & $10.08 \pm 0.066$ \\
\hline & & & Methyl red & $10.08 \pm 0.063$ \\
\hline & & & Phenol red & $10.07 \pm 0.097$ \\
\hline & & & Roselle's corolla extract & $10.07 \pm 0.059$ \\
\hline \multirow[t]{12}{*}{2} & \multirow{12}{*}{$\begin{array}{l}\mathrm{CH}_{3} \mathrm{COOH} \\
\mathrm{Vs} \\
\mathrm{NaOH}\end{array}$} & \multirow[t]{4}{*}{$0.25 \mathrm{M}$} & Phenolphthalein & $10.83 \pm 0.078$ \\
\hline & & & Methyl red & $10.77 \pm 0.091$ \\
\hline & & & Phenol red & $10.63 \pm 0.088$ \\
\hline & & & Roselle's corolla extract & $10.83 \pm 0.091$ \\
\hline & & \multirow[t]{4}{*}{$0.50 \mathrm{M}$} & Phenolphthalein & $10.78 \pm 0.075$ \\
\hline & & & Methyl red & $10.83 \pm 0.068$ \\
\hline & & & Phenol red & $10.92 \pm 0.076$ \\
\hline & & & Roselle's corolla extract & $10.93 \pm 0.058$ \\
\hline & & \multirow[t]{4}{*}{$1.00 \mathrm{M}$} & Phenolphthalein & $10.88 \pm 0.065$ \\
\hline & & & Methyl red & $10.69 \pm 0.068$ \\
\hline & & & Phenol red & $10.76 \pm 0.061$ \\
\hline & & & Roselle's corolla extract & $10.89 \pm 0.063$ \\
\hline
\end{tabular}


DOI: 10.5281/zenodo.3464396

\begin{tabular}{|c|c|c|c|c|}
\hline S.N. & Titration & Strength & Indicator & $\begin{array}{l}\text { Mean t-Value of } \\
\text { Titrations } \pm \text { SD }\end{array}$ \\
\hline \multirow{12}{*}{3} & \multirow{12}{*}{$\begin{array}{l}\mathrm{NaOH} \\
\mathrm{Vs} \\
\mathrm{NaHCO}_{3}\end{array}$} & \multirow{4}{*}{$0.25 \mathrm{M}$} & Phenolphthalein & $10.93 \pm 0.068$ \\
\hline & & & Methyl red & $10.87 \pm 0.051$ \\
\hline & & & Phenol red & $10.83 \pm 0.080$ \\
\hline & & & Roselle's corolla extract & $10.73 \pm 0.071$ \\
\hline & & \multirow{4}{*}{$0.50 \mathrm{M}$} & Phenolphthalein & $10.98 \pm 0.055$ \\
\hline & & & Methyl red & $10.88 \pm 0.058$ \\
\hline & & & Phenol red & $10.90 \pm 0.066$ \\
\hline & & & Roselle's corolla extract & $10.98 \pm 0.058$ \\
\hline & & \multirow{4}{*}{$1.00 \mathrm{M}$} & Phenolphthalein & $10.85 \pm 0.055$ \\
\hline & & & Methyl red & $10.79 \pm 0.058$ \\
\hline & & & Phenol red & $10.96 \pm 0.051$ \\
\hline & & & Roselle's corolla extract & $10.99 \pm 0.053$ \\
\hline \multirow{12}{*}{4} & \multirow{12}{*}{$\begin{array}{l}\mathrm{CH}_{3} \mathrm{COOH} \\
\mathrm{Vs} \\
\mathrm{NaHCO}_{3}\end{array}$} & \multirow{4}{*}{$0.25 \mathrm{M}$} & Phenolphthalein & $10.83 \pm 0.068$ \\
\hline & & & Methyl red & - \\
\hline & & & Phenol red & \\
\hline & & & Roselle's corolla extract & - \\
\hline & & \multirow{4}{*}{$0.50 \mathrm{M}$} & Phenolphthalein & $10.85 \pm 0.075$ \\
\hline & & & Methyl red & - \\
\hline & & & Phenol red & \\
\hline & & & Roselle's corolla extract & - \\
\hline & & \multirow{4}{*}{$1.00 \mathrm{M}$} & Phenolphthalein & $10.90 \pm 0.075$ \\
\hline & & & Methyl red & \\
\hline & & & Phenol red & - \\
\hline & & & Roselle's corolla extract & - \\
\hline
\end{tabular}

\section{Results and Discussion}

The alcoholic solution of proposed indicator Roselle's corolla extract was screened for its use as an acid-base indicator and the results were compared with that obtained using phenolphthalein, methyl red and phenol red for strong acid-strong base $(\mathrm{HCl}$ and $\mathrm{NaOH})$, weak acid-strong base $\left(\mathrm{CH}_{3} \mathrm{COOH}\right.$ and $\left.\mathrm{NaOH}\right)$, strong acid -weak base $\left(\mathrm{HCl}\right.$ and $\left.\mathrm{NaHCO}_{3}\right)$ and weak acid-weak base $\left(\mathrm{CH}_{3} \mathrm{COOH}\right.$ and $\left.\mathrm{NaHCO}_{3}\right)$ titrations. The equivalence point of the titrations using Roselle's corolla extract is almost close or coincides with that of phenolphthalein, methyl red and phenol red for strong acid-strong base, strong acid weak base and weak acid strong base titrations but not in the titration of weak acid and weak base as shown in Table 2.

Acid base titrations were carried out to ensure that the proposed colour of standard indicators like phenolphthalein, methyl red etc. reappears in titrations even after reaching the end point, but this is not happen in the case of this Roselle's corolla extract indicator. Therefore, use of alcoholic solution of this indicator could be effectively employed as an alternative to the synthetic indicators for three titrations. In other words usefulness of this indicator in strong acid- strong base was found 
to be more significant over standard indicator as it gives sharp colour change and very slight standard deviation.

\section{Conclusions}

The study revealed that the Roselle's corolla ethanolic extract can be used as a substitute to the existing acid base indicators due to its advantages like simple preparation, reversible sharp colour change in strong acid-strong base, strong acid weak base and weak base strong acid titrations, effective performance and ability to produce accuracy and precision in results. However, it is ineffective as indicator in case of weak acid weak base titrations.

\section{References}

[1] Siti Nuryanti, Sabirin Matsjeh, Chairil Anwar, Tri Joko Raharjo and Baharuddin Hamzah, European Journal of Chemistry 2013, 4 (1) 20-24

[2] Amor, B.; Allaf, K. J. Food Chem. 2009, 115, 820-825.

[3] Ologundudu, A.; Ologundudu, A. O.; Ololade, I. A.; Obi, F. O. Afr. J. Biochem. Res. 2009, 3(4), 140-144

[4] R.F.Pagariya, AJANTA 2019 Vol. 8 (1), 148-152

[5] Harborne, J. B. Phytochemical Methods. A Guide to Modern Techniques of Plant Analysis, 2nd edition, Chapman \& Hall, 1984.

[6] Torskangerpoll; Andersen, Q. M. J. Food Chem. 2004, 89, 427-444.

*Corresponding author.

E-mail address: rfp.pagariya@ gmail.com 